\title{
Traumatic Occlusion: Potential Etiologic Risk Factor Leading to a Destructive Periodontal Disease
}

\author{
KINA, José Ricardo*, KINA, Eunice FumicoUmeda ${ }^{\dagger}$ \\ *Division of Periodontics, Department of Surgery and Integrated Clinic, Dental School of Aracatuba \\ University of Sao Paulo State - "Julio de Mesquita Filho" - UNESP, Brazil. \\ †Private Practice. Rua Tiradentes 956, Vila Mendonça Araçatuba-SP. \\ *kinajr@hotmail.com \\ †eunicekina@hotmail.com
}

\section{Abstract}

The etiology of periodontal disease is multifactorial and to be treated it is necessary to diagnose, to control or to eliminate all the etiologic factors. The relevance of this study is to show the necessity to know, to diagnose, to understand all etiological factors of a determinated periodontal disease. It seems to be important, to control or to eliminate them, therefore allowing the treatment of the sequelae of periodontal disease.As a result,we analyze and discuss how, in some individuals, occlusal traumatism may act together with bacteria to produce a localized periodontal disease. This report also discusses the possibilities of treatment to control the evolution of periodontal disease.

KeyWords: Bacteria; periodontitis; etiology; dental occlusion, diagnostic, predisposing factor.

\section{INTRODUCTION}

The periodontal disease etiology is multifactorial and evidences indicate that bacterial plaqueplays an essential role as primary and principal etiologic agent to induce inflammatory processes in marginal soft tissues around the teeth ${ }^{1-7}$. Althoughbacteria are critical to developing a periodontal disease,bacteria alone seem to be insufficient to induce a periodontaldisease; a susceptible host is necessary, and host susceptibilityas local and/ or general predisposing factors are essential determinants ofdisease status ${ }^{8-13}$. Thepredisposing factor may be an intrinsic feature related with an augmented rate of a subsequentlyoccurring disease, but alone it does not induce thedisease. In periodontal disease, the predisposing factors may be defined as local factor which may facilitate accumulation of bacterial plaque and/or some damage that affect periodontal tissues leading to local low resistance and fragility. They may also be systemic factors, which may be responsible for providing interference in the inflammatory process ${ }^{14-15}$. The diagnostic of all etiologic factors is criticalto treat any disease. An accurate diagnosis is often essential to developing a well-designed and appropriate treatment plan that when implemented leads to a resolution of the patient's periodontaldisease infection. Thus the principal aim of this study is toanalyze and discuss how, in some individuals, occlusal traumatism may act together with bacteria to produce a localized periodontal disease. This report also discusses the possibilities of treatment to control the evolution of periodontal disease.

\section{CASE REPORT}

A 35-year old male individual was referred to the private dental office with a localized periodontal disease involving the lower left first molar. The patient's main complaint was pain in the affected region. Clinical examination showed a suppurated deep periodontal pocket in the mesial side of the affected tooth and radiographic examination showed a radiolucent area around this tooth (Figure 1). In the anamnesis the individual seems to be in health condition and the systemic evaluation was entirely normal as well as other diagnostic 
tests were negative.The diagnosis of this localized periodontal disease was a challenge. Normally, when the mandibles moves laterally to the left side, the lower posterior teeth leave their contact with the upper teeth and travel sideways down a path dictated by the condyles in back and by anterior guidance in the front. However, the occlusal analysis of this case showed that the incisal edge of the upper left canine was worn down exposing the dentine, compromising the anterior guidance and promoting left lateral excursion interference over the lower left first molar (Figure 2). This occlusal interference associated with bacterial plaque were diagnosed as the etiological factor that lead to a localized periodontal disease in the lower left first molar. To promote the treatment of any disease it is very important to eliminate or to control all etiological factors which conducted to the disease. After the informed consent of the patient the treatment plan was executed.In this case to treat the localized periodontal disease the first step was setting up mechanisms to ensure ongoing monitoring and evaluation of the bacterial plaque level and the reconstruction of the anterior guidance to establish control over all etiologic factors which were diagnosed (Figure 4). The second step was the treatment of the sequelae of the periodontal disease by applying regenerative periodontal surgery utilizing the autogenous bone graft, harvested from external oblique line of the mandible and guided tissue regeneration technique ${ }^{16}$ (Figure 5, 6, and 7).The individual is keeping under periodic control including periodontal and pulpal examination of the tooth involved along 2 years and 3 months (Figure 8).

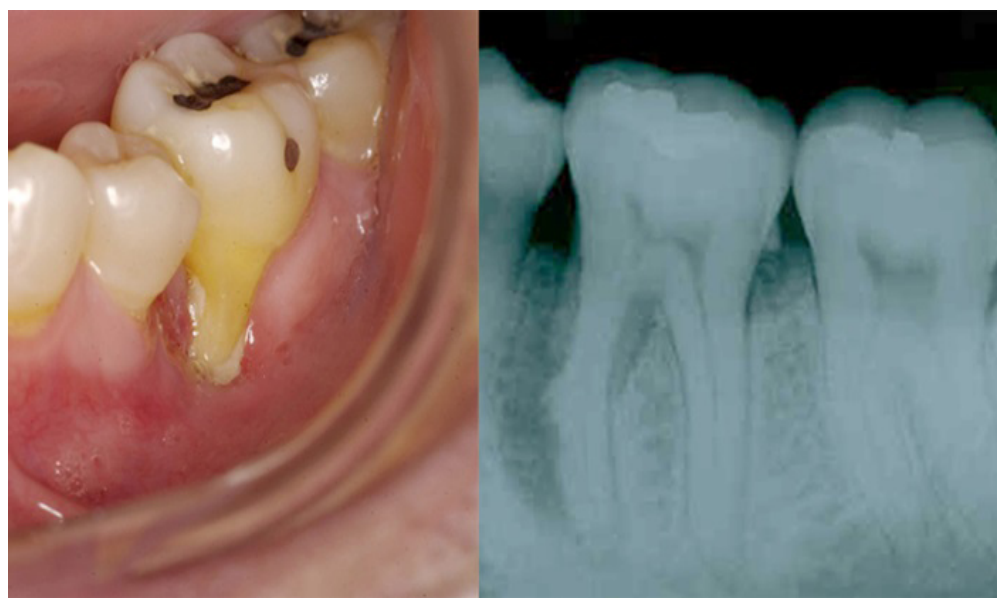

Fig1. Clinical and radiographic aspects of localized periodontal disease in tooth 36.

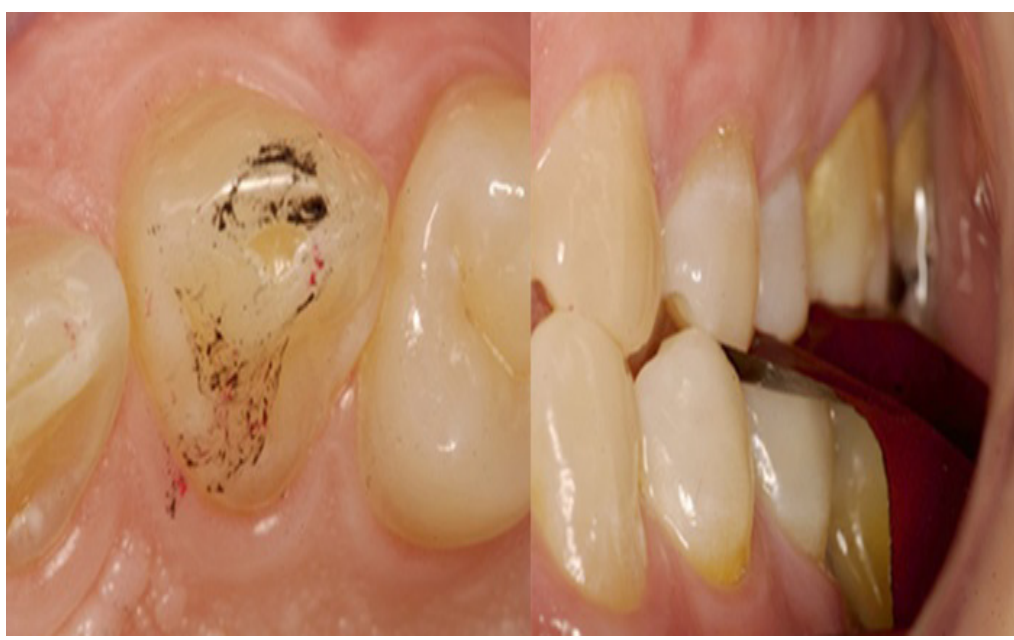

Fig2. The wear down of the incisal edge of canine exposing dentine, promoving left lateral excursion interference over tooth 36. 
Traumatic Occlusion: Potential Etiologic Risk Factor Leading to a Destructive Periodontal Disease

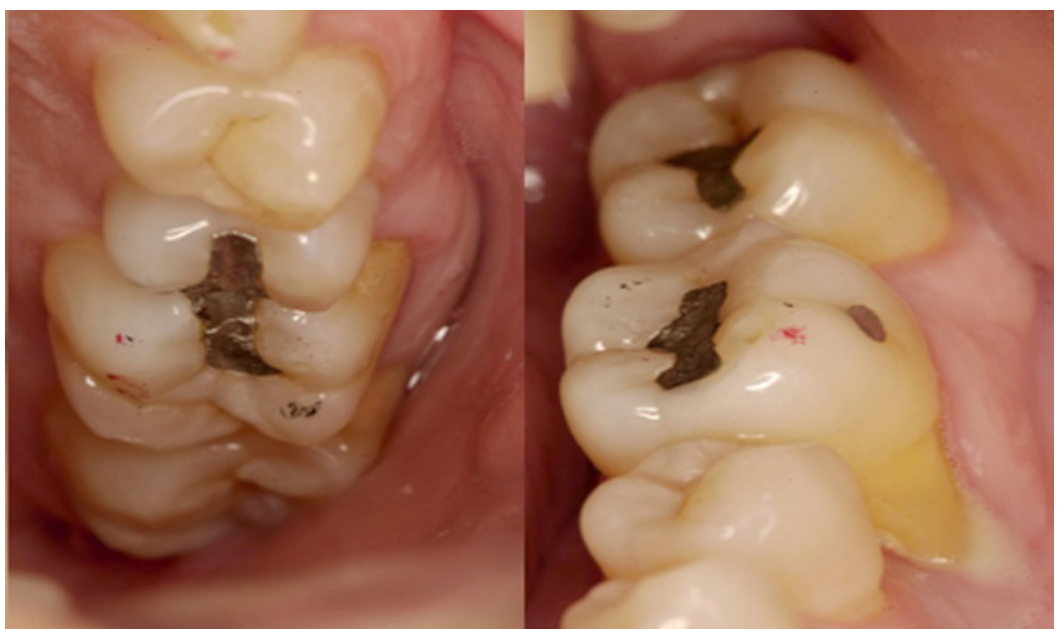

Fig3. Occlusal interference over teeth 36 against tooth 26.

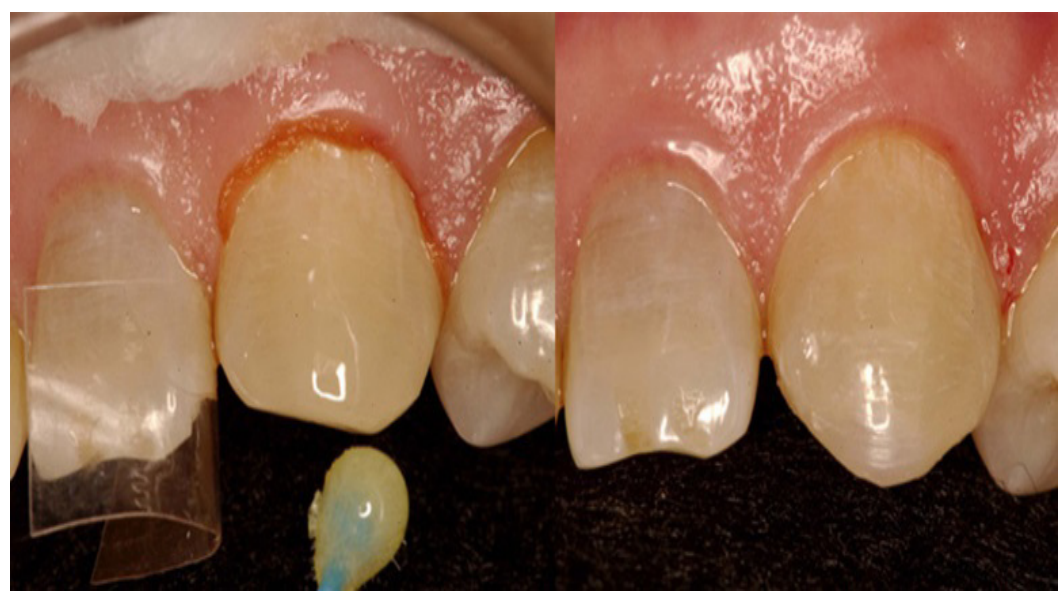

Fig4. Reconstruction of the incisal edge of canine by applying resin composite to harmonize the anterior

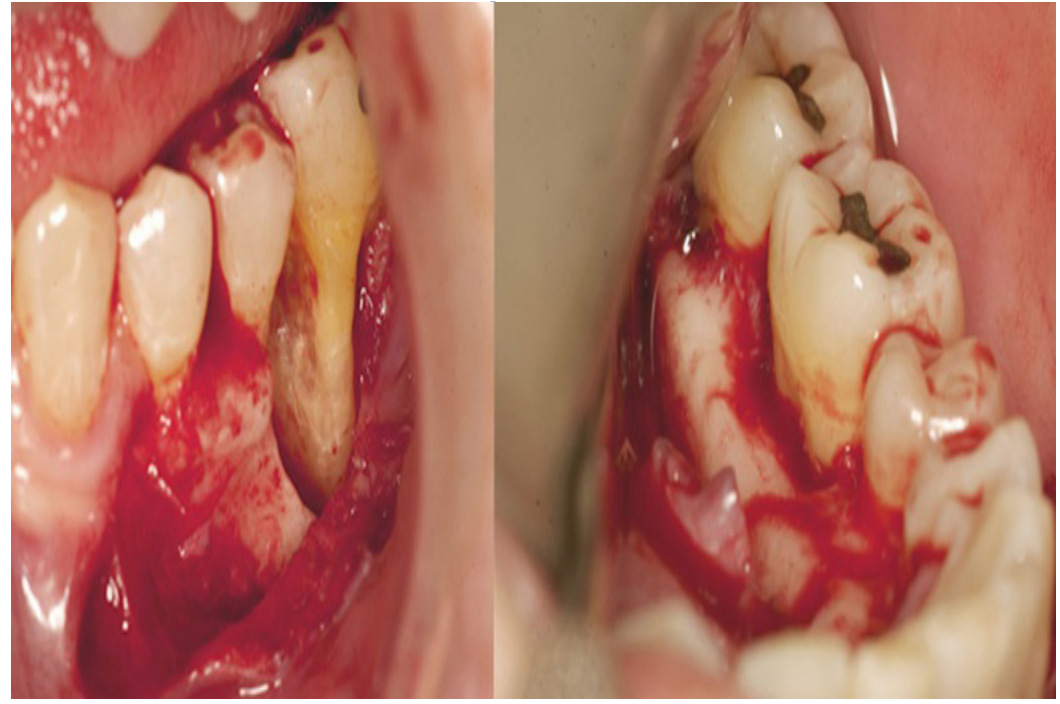

Fig5. Periodontal bone defect around tooth 36. 
Traumatic Occlusion: Potential Etiologic Risk Factor Leading to a Destructive Periodontal Disease

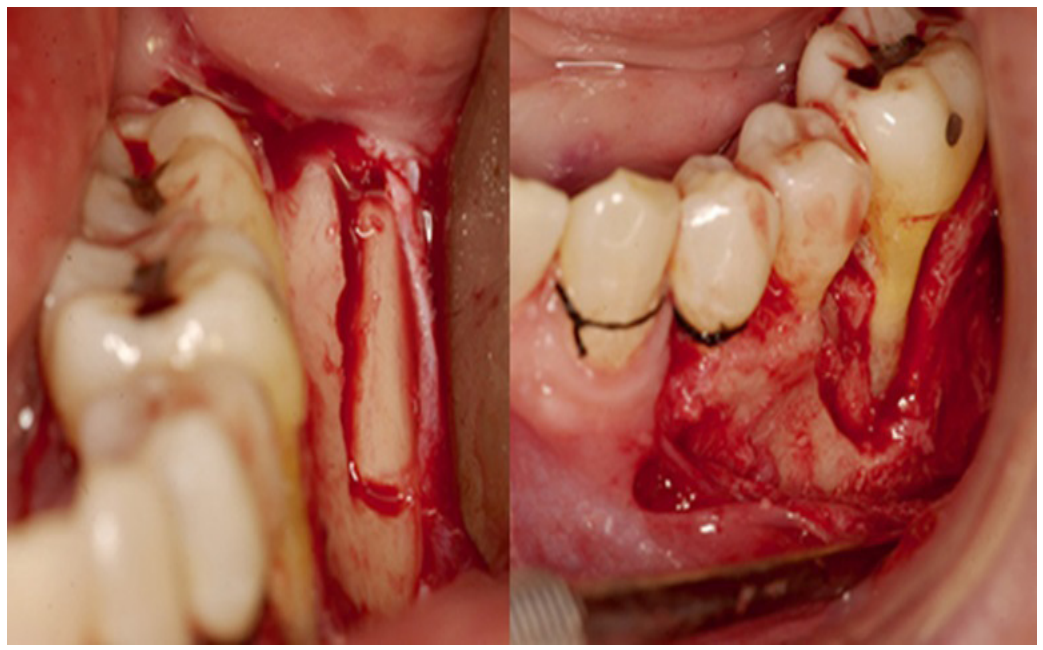

Fig6. Autogenous bone harvested from external oblique line and placed in periodontal bone defect.

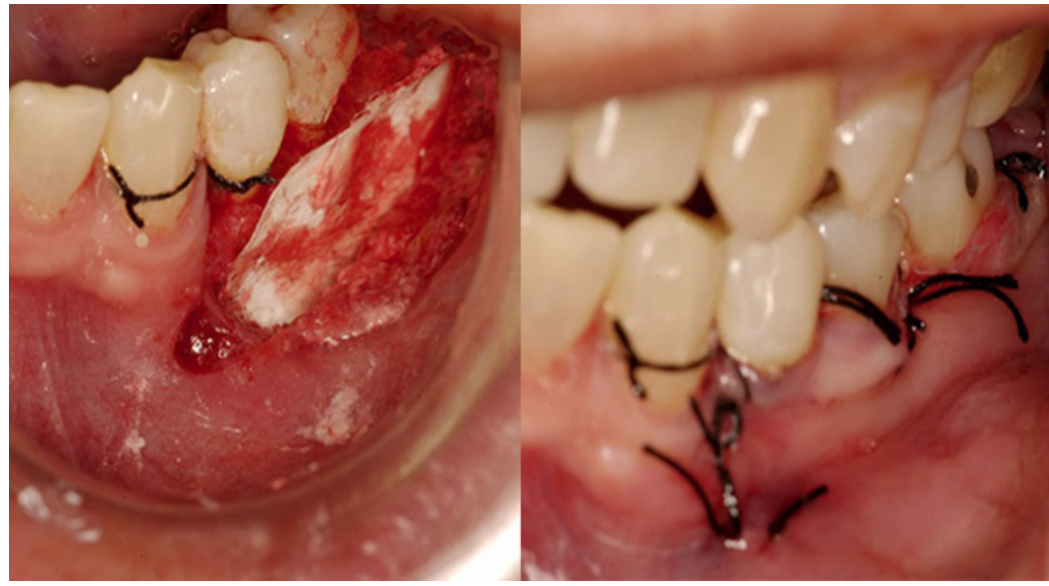

Fig7. Membrane for guided tissue regeneration and suture to achieve total tissue coverage.

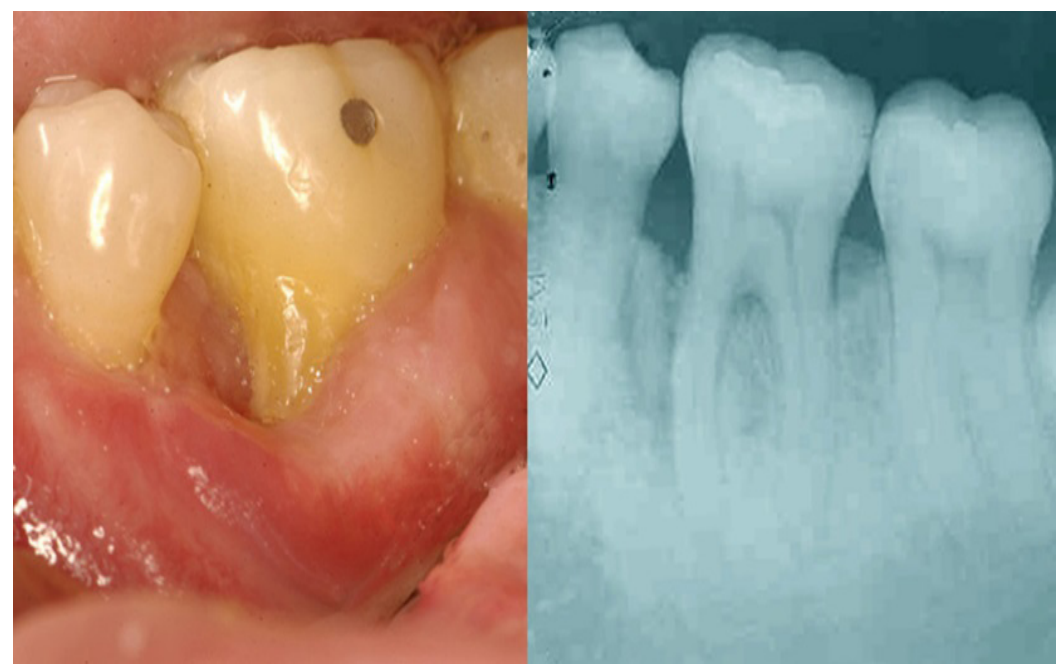

Fig8. 2 year and 3 months of clinical and radiographic postoperative view showing minimized recession and radiodense bone evidence in the area of original defect. 


\section{DISCUSSION}

Etiology encompasses the sum knowledge relating to the causes of a disease. The concepts of the cause of inflammatory gingival and periodontal disease are a complex interaction of bacteria with local oral environmental factors, systemic factors and emotional factors ${ }^{1,6-15,17}$. Although bacteria and other predisposing factors undoubtedly are related etiologically to the periodontal diseases, efforts to diagnose mainly the other predisposing factors are very complicated ${ }^{10,12,14-15,17}$.It may be impossible to distinguish the features of the pathogenesis that result from a various extrinsic factors, such as bacteria with destructive host defensive mechanism ${ }^{10-11}$. Inflammatory gingival and periodontal disease belong to a family of long-term chronic inflammatory diseases intercalated with the short inflammatory destructive acute phase that is impossible up to now to foresee ${ }^{15,18-19}$. The necessity of bacteria and predisposing factors acting together to induce periodontal disease may explain why periodontal disease is restricted to one tooth or a group of teeth or occasionally only in one side of the same tooth, and rarely produce equal destruction in all teeth in the same patient ${ }^{15,18}$. The periodontium is the primary seat of several inflammatory lesions that may differ from one another etiologically in their natural histories, but may exhibit similar histopathologic manifestations ${ }^{15,18-25}$.Thus to treat periodontal disease to provide a long state period of health, it is very important setting up mechanisms to ensure bacterial plaque control and also mechanisms to diagnose, to eliminate and/or to control all etiological predisposing factors involved in the disease determination ${ }^{1,6-14}$, In this case in particular, it was very important to establish the correct diagnoses of etiological predisposing factors that was the occlusion, to adequately treat the localized periodontal disease, because before starting the initial destructive phase of localized periodontal disease in the lower left first molar, almost the same commensal bacterial forms were probably colonizing all the teeth of the patient $t^{1-7}$. When the inflammatory acute phase triggered the initial periodontal destruction and periodontal pocket formation, maybe the unique different factor acting over the lower left first molar was the occlusal trauma. Every individual with a preserved natural occlusion, presents a deleterious contact with the centric and sometimes in eccentric relation, and is almost impossible to remove all the interfering contacts promoting a stable and permanent artificial condition known as centric occlusion ${ }^{25}$. Some mechanoreceptors from the periodontal ligaments maintain the proprioceptive impulses, by providing feedbacks to avoid occlusal interference ${ }^{26-27}$. The stomatognathic system suffers adaptation compensating deleterious premature contact with a habitual occlusion, where a masticatory pattern is developed with the force applied, being dissipated normally in the periodontium ${ }^{26}$. Despite a premature contact, during functional mastication, the antagonist teeth do not establish effective contact. However, during sleeping time, the individual under stress may develop eccentric bruxism, with occlusal trauma on the lower left second molar which was promoted by the wearing down of the incisal edge of the upper left canine that compromised the anterior guidance of the patient ${ }^{14}$. The association between bacterial plaque and occlusal trauma induces a localized periodontal disease and periodontal pocket development which is a favorable environment to be colonized by exogenous anaerobic and facultative bacteria ${ }^{14-15}$. This crucial event may create favorable conditions to develop abscess in the diseased area. Consequently, the main prevention of periodontitis could be the control of the etiological predisposing factors, since bacteria, which are considered as essential primary etiological factors of periodontal disease, will always be present in any individual to promote gingivitis ${ }^{1,2}$. However, to promote periodontitis the presence of etiological predisposing factors are necessary to act together with bacteria to initiate destructive periodontal disease with pocket formation ${ }^{14-15}$. The treatment of the sequelae of periodontal disease has been described intensively in the literature. ${ }^{28-29} \mathrm{Nevertheless,} \mathrm{to} \mathrm{treat} \mathrm{periodontal} \mathrm{disease,} \mathrm{the} \mathrm{essential} \mathrm{parametersalways} \mathrm{will}$ be the extreme necessity of knowing, understanding, diagnosing and controlling all etiological predisposing factors that induce bacteria to initialize destructive periodontal disease. 
Traumatic Occlusion: Potential Etiologic Risk Factor Leading to a Destructive Periodontal Disease

\section{CONCLUSION}

Whether all etiologic factors of periodontal disease could be diagnosed, controlled or eliminated the prognostic of the treatment of sequelae of the periodontal disease could be more previsible.

\section{REFERENCES}

1. Löe, H., Theilade, E. \& Jensen, S.B. (1965) Experimental Gingivitis in Man. Journal of Periodontology $36,177-187$.

2. Eastcott, A.D. \&Stallard, R.E. (1973) Sequential changes in developing human dental plaque as visualized by scanning electron microscopy. Journal of Periodontology 44, 218-224.

3. Hillam, D.G. \& Hull, P.S.(1977) The influence of experimental gingivitis onplaque formation. Journal of Clinical Periodontology 4, 56-61.

4. Theilade, E. (1986) The nonspecific theory in microbial etiology of inflammatory periodontal diseases. Journal of Clinical Periodontology 13, 905-111.

5. Theilade, E. \&Theilade, J. (1985) Formation and ecology of plaque at different locations in the mouth. Scandinavian journal of dental research 93, 90-95.

6. Theilade, E., Wright, W.H., Jensen, S.B. \&Löe, H. (1966) Experimental gingivitis in man. II. A longitudinal clinical and bacteriological investigation. Journal of Periodontal Research 1, 1-13.

7. Theilade, J. \&Attström, R. (1985) Distribution and ultrastructure of subgingival plaque in beagle dogs with gingival inflammation. Journal of Periodontal Research 20,131-145.

8. Alwaeli, H.A. \& Al-Jundi, S.H. (2005) Periodontal disease awareness among pregnant women and its relationship with socio-demographic variables. International Journal of Dental Hygiene3, 74-82.

9. Monteiro da Silva, A.M., Newman, H.N., Oakley, D.A. \& O'Leary, R. (1998) Psychosocial factors, dental plaque levels and smoking in periodontitis patients. Journal of Clinical Periodontology 25, 517-523.

10. Altman, L.C., Page, R.C., Vandesteen, G.E., Dixon, L.I., Bradford, C. (1985) Abnormalities of leukocyte chemotaxis in patients with various forms of periodontitis. Journalof Periodontal Research20, 553-563.

11. Attström, R. \& Schroeder, H.E. (1979) Effect of experimental neutropenia on initial gingivitis in dogs. Scandinavian Journal of Dental Research 87, 7-23.

12. Buckley, L.A. (1981) The relationships between malocclusion, gingival inflammation, plaque and calculus. Journal of Periodontology 52, 35-40.

13. Cohen, D.W. \& Goldman, H.M. (1960) Clinical observations on the modification of human oral tissue metabolism by local intraoral factors. Annals of the New York Academy of Sciences 29, 68-95.

14. Kina JR, Suzuki TYU, Kina EFU, Kina J, Kina M (2016) Non-Inflammatory destructive Periodontal Disease. Open Dent J 10:50-57.

15. Kina JR, Suzuki TYU, Kina J, Kina M, Kina EFU (2013) Reparativephase events on periodontal disease progression: interpretationand considerations. Int J Microbiol Res 5: 439-444.

16. Caton, J., Wagener, C., Polson, A., Nyman, S., Frantz, B., Bouwsma, O., Blieden, T. (1992) Guided tissue regeneration in interproximal defects in the monkey. The International Journal of Periodontics \& Restorative Dentistry 12, 266-277. 
Traumatic Occlusion: Potential Etiologic Risk Factor Leading to a Destructive Periodontal Disease

17. Leresche, L. \&Dworkin, S.F. (2002) The role of stress in inflammatory disease, including periodontal disease: review of concepts and current findings. Periodontology 2000 30, 91-103.

18. Socransky, S.S., Haffajee, A.D., Goodson, J.M., Lindhe, J. (1984) New concepts of destructive periodontal disease.Journal of Clinical Periodontology 11, 21-32.

19. Fine, D.H. \& Mandel, I.D. (1986) Indicators of periodontal disease activity: an evaluation. Journal of Clinical Periodontology 13, 533-546.

20. Haffajee, A.D., Socransky, S.S. \& Goodson, J.M. (1983) Clinical parameters as predictors of destructive periodontal disease activity. Journal of Clinical Periodontology 10, 257-265.

21. Goodson, J.M., Tanner, A.C., Haffajee, A.D., Sornberger, G.C., Socransky, S.S. (1982) Patterns of progression and regression of advanced periodontal disease. Journal of Clinical Periodontology9, 472-481.

22. Davenport, R.H. Jr, Simpson, D.M. \&Hassell, T.M. (1982) Histometric comparison of active and inactive lesions of advanced periodontitis. Journal of Periodontology53, 285-295.

23. Becker, W., Berg, L. \& Becker, B.E. (1979) Untreated periodontal disease: a longitudinal study. Journal of Periodontology 50, 234-244.

24. Garant PR \& Cho MI. Histopathogenesis of spontaneous periodontal disease in conventional rats. I. Histometric and histologic study. J Periodontal Res. 1979 Jul;14(4):297-309.

25. Freedman HL, Listgarden MA, Taichman NS. Electron microscopic features of chronically inflamed human gingiva. Journal of Periodontal Research 1968; 3:313-327.

26. Dawson PE. Evaluation, diagnosis and treatment of occlusal problems. 2nd ed. St. Louis: Mosby; 1989. pp. 72-84.

27. Nakanishi H., Seki Y., Kohno T., Muramoto T., Toda K., Soma K. Changes in response properties of periodontal mechanoreceptors after experimental orthodontic tooth movement in rats. Angle Orthod. 2004;74(1):93-99.

28. Polson, A.M. \&Heijl, L.C. (1978) Osseous repair in infrabony periodontal defects.Journal of Clinical Periodontology 5, 13-23.

29. Tonetti, M.S., Pini Prato, G. \&Cortellini, P. (1993) Periodontal regeneration of human infrabony defects. IV. Determinants of healing response. Journal of Periodontology64, 934-940.

Citation: KINA, José Ricardo, KINA, Eunice FumicoUmeda, "Traumatic Occlusion: Potential Etiologic Risk Factor Leading to a Destructive Periodontal Disease". American Research Journal of Dentistry; 1(1): 9-15.

Copyright (C) KINA, José Ricardo, KINA, Eunice FumicoUmeda, This is an open access article distributed under the Creative Commons Attribution License, which permits unrestricted use, distribution, and reproduction in any medium, provided the original work is properly cited. 